\title{
On Pre-training for Climate Change Induced Migration from the Pacific: Lessons from the Marshall Islands
}

\author{
Nagisa Yoshioka (Corresponding author) \\ Graduate School of Frontier Sciences, The University of Tokyo 5-1-5 Kashiwano-ha \\ Kashiwa, Chiba 277-8563, Japan \\ E-mail:6272167605@edu.k.u-tokyo.ac.jp
}

Received: January 16, 2017 Accepted: February 21, 2017 Published: March 29, 2017

doi:10.5296/ijssr.v5i1.10594 URL: http://dx.doi.org/10.5296/ijssr.v5i1.10594

\begin{abstract}
This study aims to suggest another view of the so-called "climate refugee", especially those from the Small Island Developing States (SIDS) in the Pacific Ocean. Although many studies have been conducted on the legal aspects of the climate refugees' situations, little has been studied about how they succeed in re-establishing their livelihoods after relocation. Unlike migrations forced by other causes, the future migrations induced by sea level rise have a long lead time which gives the people involved the opportunity to develop the skills necessary to adjust to their new lives. This paper examines whether "pre-training" opportunities are sufficient in those countries from which climate refugees are most likely to come. The author focuses on the Republic of the Marshall Islands, one of the small island countries in the Pacific being threatened by environmental changes such as rising sea level, high tides, and drought. Due to a unique situation allowing the Marshallese people to move to the United States without a visa, many people do so each year under the free association partnership. However, some of these migrants fail to adjust to the United States and come back to their home islands, possibly due to a lack of skills. Given that more climate refugees are likely in the future, pre-training that provides essential skills to benefit future climate refugees is necessary. Through key informant interviews in the Marshall Islands, it seems that such training opportunities are currently limited, but have great potential to flourish.
\end{abstract}

Keywords: climate change, livelihood rehabilitation, migration, refugee, Republic of the Marshall Islands 


\section{Introduction}

\subsection{Climate Change Induced Migration from Small Island Developing States in the Pacific}

Over the past few decades, a considerable number of studies have been undertaken to examine how people adapt to climate change. Small Island Developing States (SIDS) face the most serious crises in climate change, as adaptation to rising sea level is an urgent issue for them. The latest annual report of the Intergovernmental Panel on Climate Change (IPCC) states that "sea level rise poses one of the most widely recognized climate change threats to low-lying coastal areas on islands and atolls" (IPCC, 2013). In recent years there has been a renewal of interest in climate change induced human migration, whose subjects are known as "climate refugees." A large number of studies have explored issues related to the legal rights of climate refugees. Refugee Convention was established in 1951 to protect people who are unable or unwilling to return to their home countries because they face fear of being persecuted due to race, religion, nationality, political opinion, and membership in a particular social group. Besides, the United Nations Framework Convention on Climate Change (UNFCCC) guarantees human rights and humanitarian aid for climate refugees and imposes the responsibility of protecting those guarantees on the home country, host country and the international community. Docherty and Giannini (2009) proposed the establishment of a new convention as a protocol to either the Refugee Convention or the UNFCCC. Biermann and Boas (2010) suggested global governance reform on the recognition, protection, and resettlement of climate refugees. In addition to these, Williams (2008) explains how a regional-oriented regime under the UNFCCC could remedy the current protection gap within the existing international legal framework. As a result of all this, the legal framework surrounding the climate refugee has provoked a great deal of controversy.

On the other hand, we should note that refugees have always migrated for a variety of reasons, not always directly linked with climate change. In that sense, if climate change induced migrations are not the only migrations taking place, then it is very difficult to identify climate refugees. Therefore, the debate on the legal framework of climate refugees has remained controversial for many years. Furthermore, we have to consider the fact that some people refuse to be called climate refugees, because the term "refugee" generally defines people fleeing their countries because of conflict, violence, or persecution. It is not necessary for this paper to enter into a detailed discussion of the legal definition of a climate refugee. The author assumes that people will move to other countries because of the adverse effect of climate change and aims to discuss what international society can and should do to address this problem.

\subsection{Migration as an Opportunity for Livelihood Re-Establishment of Climate Refugees}

Great effort has been made to resolve the legal questions related to climate refugees. What seems to be lacking, however, is consideration of how these people will re-establish their livelihoods after they migrate. Climate refugees often carry the stereotypical image of an unfortunate or miserable people being relocated unwillingly. However, this study suggests that a change in mindset can allow the migration to be regarded and approached as an opportunity. 
The Kiribati government has already started preparing for the possibility of large-scale migration (McNamara, 2015; Donner \& Webber, 2014). Anote Tong, the former Kiribati President, declared the "Migration with Dignity" policy as part of Kiribati's long-term nation-wide relocation strategy. This policy aims to avoid forced relocation by providing better education and training that will make it easier to get jobs in neighboring developed countries and in this way encourages voluntary migration now or in the near future. My suggestion is consistent with this concept. In order to ensure that a migrant's dignity is not impaired, it is necessary for them to take an optimistic view of their migration.

\subsection{Long Preparation Time and Pre-Migration Training}

The sea level is rising very slowly, and the movement of migrants is expected to continue over a few decades. This, unlike the situation for people forced to migrate because of natural disaster, civil war, or industrial accident, gives a relatively long lead time for the future climate refugees from small island nations, sufficient to allow the future migrants to prepare and acquire the skills that are necessary for successful re-establishment of their livelihoods after migration. This, in turn, allows them to consider their future migration more positively (Nakayama, Yoshioka, Fujibayashi, \& Bruch, 2016).

\subsection{The Case of the Marshall Islands}

The Republic of the Marshall Islands (RMI) is one of many small atoll countries in the Pacific which are being threatened by environmental change. The Marshall Islands are located near the equator in the Pacific Ocean. The entire population is about 70 000; approximately 27000 people live in Majuro, the capital city of RMI (CIA, 2016; RMI, 2011). In the Marshall Islands, shoreline erosion caused by the rising sea level is already a significant problem, and by the end of the century, the projected sea level rise is $0.35 \mathrm{~m}(0.23$ to $0.47 \mathrm{~m}$ ) in total (GFDRR, 2011). RMI is also known as the country that historically experienced forced migration because of the nuclear testing by the U.S. Army from 1946 to 1958. Today, Marshallese people can migrate to the United States without a visa and with no time restraints under the Compact of Free Association (COFA), enacted in 1986. This is an international agreement which establishes and governs the relationships of free association between the United States and RMI, the Federated States of Micronesia, and Palau. The Compact Trust Fund, which is financial aid provided by the United States under COFA, amounted to 90.2 million U.S. dollars at the end of 2013, and total grants accounted for almost $60 \%$ of Marshallese government revenue - meaning that RMI depends considerably on financial assistance (IMF, 2014). Because of the free association relationship, approximately 9,000 people have moved to the United States (UNICEF 2014). Although they seek better jobs, education, and health services, some people have been forced to return to the islands every year. They simply could not adjust to their new lives in the United States due to lack of vocational skill, the language barrier, and culture shock. In Hawaii, some of them became homeless, which has created a social problem for the local people there. Given the likelihood that there will be more climate refugees in the future, it is important to determine how best to help migrants overcome these difficulties and succeed in re-establishing their livelihoods. The long preparation times, as mentioned above, afford an opportunity to provide 
people with some training to prepare them for the future.

\section{Objective}

This paper looks at the training or education process from the perspective of its effectiveness as a preparation for climate change induced migration. My research interest is to explore how future climate refugees can migrate to other countries and re-establish their new lives with dignity or satisfaction, and make undesirable out-migration a positive opportunity. The question I try to answer is whether people in the Pacific Islands have enough opportunities available to them to meet these requirements. I turn to a case study of the Marshall Islands, one of the Pacific island countries facing climate change, to find out the answer to this question.

\section{Method}

This paper is based on field research conducted in Majuro, the capital city of RMI. I conducted interviews from October 18 to 22, 2016 with professors and practitioners of human migration who are familiar with the current situation of the Marshallese population. Interviews were conducted at the College of the Marshall Islands (CMI) and at the Marshall Islands campus of the University of the South Pacific (USP-MIC), the only institutions that provide post-secondary education in the Marshall Islands. Interviews also took place at the Marshall Islands office of the International Organization for Migration (IOM), The Republic of the Marshall Islands Environmental Protection Authority, and a local NGO.

According to the National Review of Education published by the Ministry of Education of RMI (MOE-RMI) in 2014, the total number of students 14-25 years of age attending CMI and USP-MIC accounted for about $84 \%$ (Note 1) of the total number of youth aged 14-25 who were unemployed and received post-secondary education (the rest of the student enrolled other colleges or universities outside the Marshall Islands supported by the Marshall Islands Scholarship, Grant and Loan Board). From this, it may be concluded that the current resources are sufficient to provide education to young people to develop the skills they may need for future migration. What has to be noted, however, is that the total number of students aged 14-25 attending CMI and USP-MIC account for only $7.7 \%$ of the total RMI population of that age (13,204 at the time of the 2011 Census).

The ten interviewees include six CMI professors (from the departments of Business Studies, Developmental Education, Science, Technology and Mathematics, Nursing \& Allied Health, and Liberal Arts), a USP professor, and three practitioners (from IOM, The Republic of the Marshall Islands Environmental Protection Authority, and a local NGO). They were answered three main questions to identify their perception of certain issues related to migration:

a) Why have some Marshallese people come back to the Islands from the United States?

b) What kind of skills do people need to adjust to a new country?

c) Are pre-migration training practices (such as vocational training) sufficient in the Marshall Islands? 
The question (a) and (b) were set to identify the current obstacles in adjusting the new living place. The answers to the questions (c) was used to test people's perception about sufficiency of pre-training for the future migrant. The author, the sole interviewer recorded full interviews and compared results with my hypothesis that people recognize that the opportunities of training to succeed in livelihood re-establishment are not sufficient in the Marshall Islands.

No previous studies have tried to shed light on the present situation in the SIDS in terms of preparation for future migration caused by climate change. This investigation does not aim to provide objective evidence; the answers provide subjective opinions on the issues. Therefore, the limitation of this study is that it is difficult to conclude that the actual opportunities of pre-training is insufficient only by using results of interviews. However, these opinions do provide some indication of what the international community should do to deal with climate refugees in the future.

\section{Result}

The interviews revealed how professors and practitioners in the Marshall Islands regard the present domestic status of preparation for future migration. The main reason given to explain why a lot of Marshallese people have returned to their homeland is that high living expenses are a huge obstacle for those who have settled in the United States over the past few decades. In Springdale, Arkansas, many Marshallese work in the chicken factory where the wage level is relatively low. Even though their incomes are higher than when they lived in the Marshall Islands, the cost of living in the United States is also much higher, and their lack of vocational skill and the language barrier prevents people from getting the higher-paying jobs they need in the United States to manage the higher cost of living. The unemployment rate in the Marshall Islands population aged 15 years and older exceeds $60 \%$, which is among the highest in the Pacific island countries, and poverty rates reach more than 50\% (ADB, 2016). People in the islands, however, seldom suffer from extreme poverty because of the mutual support provided among their large families.

On the other hand, nobody interviewed expressed the opinion that there are enough opportunities for future migrants to acquire the required skills to re-establish successfully in other countries. They answered what people need to adjust the lives in the United States are languages, education, information, and finance. CMI has some vocational programs for students to study nursing, carpentry, or fishery. However, these existing programs are assumed to provide skills for local jobs and the number of students who participate in CMI's programs is still very small (MOE-RMI, 2014). Also, according to some interviewees, only a few students are fluent in English, even though all classes except for Marshallese language class in CMI are conducted in English.

The interviews also revealed that the situation has recently been improving. USP started a program in June, 2015 which provides people with the opportunity to acquire vocational skills. The Pacific Technical and Vocational Education and Training (PacTVET) project, funded by the European Union, works through a technical and vocational training curriculum to create and enhance the capacity to deal with climate change and sustainable energy 
challenges. The project expects the public sector, private sector, and non-governmental organizations (NGOs) to identify the skills required for adaptation to climate change and for developing the use of sustainable energy. Although the program was not established to directly train people in the skills they need to re-establish their livelihoods when they emigrate to other countries, it will, nevertheless, enhance the national and regional capacity to develop trainers and teachers who are able to instruct in the skills and knowledge that will be of most use to climate refugees. The CMI and USP-MIC TVET suppliers are currently developing programs to meet the needs of the country.

It is reasonable to conclude that there is room for improvement in the current status of potential migrants' vocational and language skills and in their opportunities for training in these areas. It is also the case that these circumstances are gradually changing for the better.

\section{Discussion}

The question that we should consider next is why training alone is not enough for people to prepare for their future migration from the Marshall Islands. To answer this question, we must take into account the Marshallese political and economic situation.

\subsection{Priority Matters in the Republic of the Marshall Islands}

Policies related to emigration because of climate change are not a priority for RMI. Unlike the governments of neighboring countries Kiribati and Tuvalu, the Marshallese government has not yet officially declared that their land will be submerged soon, therefore it is contradictory for the government to promote policies that assume climate change induced migration. Instead, the Marshallese government seems to prioritize other issues over immigration policy. At the $71^{\text {st }}$ session of the United Nations General Assembly held in September, 2016, Hilda C. Heine, President of the Marshall Islands listed education, economic security, and national basic social development as the government's priorities. In addition, the National Strategic Plan (NSP) of the Marshallese government (RMI, 2014) sets the priority on sustainable economic development, which governs the development plans for the agricultural, marine, tourism, and manufacturing sectors. At the same time, the government aims to improve financial services, create jobs, boost investment for the private sector. The NSP also mentions making improvements in areas of social concern such as health, food security, and environmental issues. At this point, these matters - related to the reinforcement and substantiation of national power-are of much higher priority to the Marshallese government than is migration policy.

\subsection{The "Brain Drain” of Highly Skilled Human Resources}

Improving the education system is one of the main issues for the Marshallese. Both CMI and USP-MIC provide two-year A.A./A.S. degree programs. However, students wanting to pursue bachelor's degrees must study at universities outside the Marshall Islands, most often in Fiji, Hawaii, or Guam, and many of these students do not move back home after their graduation. Docquier et al. (2009) estimated the emigration rate of college graduates from small developing countries (including non-SIDS countries) at $42.8 \%$, as compared to much lower rates of emigration of college graduates from high-income countries $(13 \%)$ or larger 
developing countries (14\%). This results in a lack of human resources to provide the skills needed to adjust to life in other countries. In the background, it seems there is a weak educational system that results in a vicious cycle of insufficient opportunities of training and lack of human resources to provide skills for better emigration. Quality education is highly prized because only a small number of youth receive post-secondary educations. Furthermore, approximately $57 \%$ of young people aged 14-25 are neither employed nor in college, and only $6 \%$ of which are supported by National Training Council, which provides out-of-school or unemployed youth with grants to support training in basic education and life skills, entrepreneurship, and technical-vocational skills (MOE-RMI, 2014). As this illustrates, development of basic education - the foundation of pre-training - is an unsolved and critical part of the Marshallese government's agenda.

\subsection{Perception of Preparedness}

Marshallese citizens can move to the United States without limit, and can go back to the islands whenever they choose. However, this "easy access" might undermine the need for preparation. Many Marshallese move to the United States without sufficient training and motivation because they can manage to lead their lives by depending on their relatives already living there. Most of them are supported by the Marshallese communities through the church. Although the physical distance from the islands to the Unites States is closer-than-expected for Marshallese people, the cultural differences are still very great. Nonetheless, people simply do not perceive education and training as important. One of the interviewees said that the Marshallese are more likely to prioritize housework or childcare, because young people have important roles in the home as family members. We have to learn to acknowledge their idiosyncratic mindsets in regard to emigration to the United States. Improvement of the Marshallese perceptions and expectations towards immigration is a key aspect of better transitions.

\subsection{Implementation of Pre-training}

It is also necessary to consider who implements pre-training. The interviews revealed that third-sector and international organizations play an important role in terms of the provision of pre-training for future migration. For example, IOM has started preparation training for future migrants in the Marshall Islands. The Migrant Resource Center (MRC), which was established under the IOM Marshall Islands Office, has provided pre-departure orientation for migrants to the United States under the free association since the Marshall Islands became an IOM member state in 2013. MRC's pre-departure orientation training covers topics such as culture, social skills, jobs, workplace, finance, and communication, which promotes understanding of the differences between the two societies. MRC aims to develop factsheets and information packages for the most popular destinations in the United States: Hawaii, Guam, and Arkansas. USP also has its own vocational training stream through Centre for Vocational and Continuing Education (CVCE). CVCE provides vocational and professional programs for post-secondary and mature students at each satellite campus of USP. Furthermore, private sector organizations in the United States and local non-governmental organizations provide consultation services and employment programs. In conclusion, there 
are many potential implementation bodies and structures for providing preparation training to mitigate the problems of future climate refugees.

\section{Acknowledgements}

This study was supported by the Sumitomo Foundation and the University of Tokyo Graduate School of Frontier Sciences.

\section{References}

Asian Development Bank. (2016). Pacific Approach, 2016-2020. Retrieved from https://www.adb.org/sites/default/files/institutional-document/190666/rcs-pacific-2016-2020. pdf

Barnett, J. (2001). Adapting to climate change in Pacific Island countries: the problem of uncertainty. World Development, 29(6), 977-993. https://doi.org/10.1016/S0305-750X(01)00022-5

Biermann, F., \& Boas, I. (2008). Protecting climate refugees: the case for a global protocol. Environment: Science and Policy for Sustainable Development, 50(6), 8-17.

Biermann, F., \& Boas, I. (2010). Preparing for a warmer world: Towards a global governance system to protect climate refugees. Global Environmental Politics, 10(1), 60-88. https://doi.org/10.1162/glep.2010.10.1.60

Burke, B. (2012, July 4). For Pacific Islanders, Hopes and Troubles in Arkansas. New York Times. Retrieved from http://www.nytimes.com/2012/07/05/us/for-marshall-islanders-hopes-and-troubles-in-arkansa s.html

Campbell, J. R. (2010). Climate Change and Population Movement in Pacific Island Countries. In B. Burson (Ed.), Climate Change and Migration in the South Pacific Region: Policy Perspectives. Institute of Policy Studies: Wellington.29-50.

Central Intelligence Agency. (2016). The world fact book (Page last updated on 2016, November 10) Retrieved from https://www.cia.gov/library/publications/the-world-factbook/ geos/rm.html

De la Croix, D., Docquier, F., \& Schiff, M. (2014). Brain drain and economic performance in Small Island Developing States. In The socio-economic impact of migration flows, 123-144. https://doi.org/10.1007/978-3-319-04078-3_6

Docquier, F., Lowell, B. L., \& Marfouk, A. (2009). A gendered assessment of highly skilled emigration. Population and Development Review, 35(2), 297-321. https://doi.org/10.1111/j.1728-4457.2009.00277.x

Docherty, B., \& Giannini, T. (2009). Confronting a rising tide: a proposal for a convention on climate change refugees. Harvard Environmental Law Review, 33, 349.

Donner, S. D., \& Webber, S. (2014). Obstacles to climate change adaptation decisions: A case 
study of sea-level rise and coastal protection measures in Kiribati. Sustainability Science, 9(3), 331-345. https://doi.org/10.1007/s11625-014-0242-z

Economic Policy, Planning, and Statistics Office. Office of the President of the Republic of the Marshall Islands. (2012). The RMI 2011 Census of Population and Housing: Summary and Highlights Only. Retrieved from https://www.doi.gov/sites/doi.gov/files/migrated/oia/reports/upload/RMI-2011-Census-Summ ary-Report-on-Population-and-Housing.pdf

Global Facility for Disaster Reduction and Recovery. (2011). Vulnerability, Risk Reduction, and Adaptation to Climate Change: Marshall Islands.

H.E. Ms. Hilda Heine. (2016, September 22). 71st session of the United Nations General Assembly General Debate. Retrieved from https://gadebate.un.org/sites/default/files/gastatements/71/71_MH_en.pdf

Intergovernmental Panel on Climate Change. (2013). Climate Change 2013: The physical science basis.

International Monetary Fund. (2014). Republic of the Marshall Islands: Staff report for the 2013 Article IV consultation, IMF Country Report No. 14/26. https://www.imf.org/external /pubs /ft/scr/2014/cr1426.pdf

Kälin, W. (2010). Conceptualising climate-induced displacement. In J. MacAdam (Ed.), Climate change and displacement: Multidisciplinary perspectives. Oxford: Hart Publishing.

McNamara, K. E. (2015). Cross-border migration with dignity in Kiribati. Forced Migration Review, 49, 62-62.

McNamara, K. E., \& Gibson, C. (2009). 'We do not want to leave our land': Pacific ambassadors at the United Nations resist the category of 'climate refugees'. Geoforum, 40(3), 475-483. https://doi.org/10.1016/j.geoforum.2009.03.006

Ministry of Education Republic of the Marshall Islands. (2014). Education for all national review. Retrieved from http://unesdoc.unesco.org/images/0022/002297/229722E.pdf

Nakayama, M., Yoshioka, N., Fujibayashi, H., \& Bruch, C. (2016). Factors affecting livelihood re-establishment of climate change induced transboundary displaced persons. International Journal of Social Science Studies, 4(9), 40-48. https://doi.org/10.11114/ijsss.v4i9.1744

Republic of the Marshall Islands. (2014). National Strategic Plan 2015-2017. Retrieved from https://www.adb .org/sites/default/files/linked-documents/cobp-rmi-2016-2018-ld-04.pdf

United Nations, DESA-Population Division and UNICEF. (2014). Migration Profiles Common Set of Indicators. Retrieved from https://esa.un.org/miggmgprofiles/indicators /indicators.htm

Warner, K., Hamza, M., Oliver-Smith, A., Renaud, F., \& Julca, A. (2010). Climate change, environmental degradation and migration. Natural Hazards, 55(3), 689-715. 
https://doi.org/10.1007/s11069-009-9419-7

Williams, A. (2008). Turning the tide: recognizing climate change refugees in international law. Law \& Policy, 30(4), 502-529. https://doi.org/10.1111/j.1467-9930.2008.00290.x

\section{Notes}

Note 1. In 2014, CMI had 768 students aged 14-25 and USP-MIC had 246. (MOE-RMI, 2014)

\section{Copyright Disclaimer}

Copyright for this article is retained by the author(s), with first publication rights granted to the journal.

This is an open-access article distributed under the terms and conditions of the Creative Commons Attribution license (http://creativecommons.org/licenses/by/3.0/). 